\title{
ANTICANCER EFFECT OF SALVIA (MARAMIA) EXTRACT ON HEp-2 CANCER CELL LINE
}

\author{
Ahmed Nabil Fahmi ${ }^{*}$, Amr H. Elbolok ${ }^{* *}$ and Naglaa M. Kamal ${ }^{* * *}$
}

\begin{abstract}
Sage (salvia) species have been used for a long time to relief pain; protect the body against viral and bacterial infection and inflammation, treatment of life-threatening diseases as heart disease, diabetes, and cancer. Many studies advocated sage species for drug development because of their recorded therapeutic effects including anti-proliferative and cytotoxic effects against malignant cells.
\end{abstract}

Objective: Evaluate the anticancer effect of salvia extract.

Materials and Methods: A pure extracts from ground leaves of salvia were added to nasopharyngeal carcinoma cell line and to normal cell line as a control.

Results: Anti-proliferative effects of Salvia showed the highest cytotoxic effect against nasopharyngeal carcinoma cell line after $28 \mathrm{~h}$ of influence. We observed no anti-proliferative effects on the healthy cell line.

Conclusions: Our results confirmed the potent genotoxic and anti-proliferative properties of Salvia against laryngeal cancer cell line.

Keywords: Sage (Salvia species), Cancer, Apoptosis, cell line, essential oils.

\section{INTRODUCTION}

One of the most dangerous human diseases is cancer which has an increased rate of mortality ${ }^{1}$. Among the effective cancer treatment modalities are surgery, chemotherapy, and radiotherapy ${ }^{2}$.
Decreased toxicity, increased effectiveness, and low cost of the herbal medicine offer better treatment modalities ${ }^{3}$.

Naturally occurring substances can modify apoptosis signaling pathways which plays an important role in the eradication of cancer cells $s^{4,5}$.

\footnotetext{
* Lecturer, Oral Pathology Department, Faculty of Oral and Dental Medicine, BeniSuef University, Egypt.

** Associate professor, Oral Pathology Department, Faculty of Oral and Dental Medicine, Minia University, Egypt.

*** Lecturer, Oral Pathology Department, Faculty of Oral and Dental Medicine, Ahram Canadian University, $6^{\text {th }}$ of

October City, Giza Egypt.
} 
The programmed cell death is applied through a pathway of self-destruction and marked by biochemical, and morphological indicators as reducing of cell volume and DNA fragmentation ${ }^{6}$. Though, researchers have attempted to discover therapeutic agents that attain their cytotoxic effects by provoking apoptosis in malignant cells ${ }^{7-9}$.

The genus Salvia, which is known as sage, is the largest member of Lamiaceae family that contains more than 900 species ${ }^{10,11}$. In the Levant, it is called Maramia ${ }^{12}$. These plants are aromatic and have flowers with various colors ${ }^{13}$. Several species of Salvia, as Salvia officinalis (common sage), are found in the Mediterranean region ${ }^{12}$.

Salvia contains different chemical compounds as terpenoids, flavonoids, and essential oils ${ }^{13}$, the compositions of the essential oil of Salvia species varied according to many factors as environmental, seasonal, and genetic factors ${ }^{14}$, this essential oil is considered an important anticancer, antimicrobial, and antioxidant agent ${ }^{15}$.

There are various reports on the cytotoxic activity of Salvia on cancer cells ${ }^{16}$. In this study we are trying to demonstrate the cytotoxic effect of salvia in vitro on laryngeal cancer cell line (HEp-2).

\section{MATERIALS AND METHODS}

\section{Plant materials}

Dried, cut leaves of Salvia (1 kg) were purchased from Jordan and deposited at the National Research Institute, laryngeal cancer cell line was obtained from the cell culture department-VACSERAEgypt.

\section{Sample preparation}

15 grams of pure extracts were obtained from ground leaves of salvia using different solvents.

Salvia extracts were added to nasopharyngeal carcinoma cell line and to a healthy cell line as a control. PCR was done after incubation for 24 and $48 \mathrm{~h}$ at $37^{\circ} \mathrm{C}$.

\section{PCR methodology}

Using quantitative real- time PCR, DNA and RNA were extracted from cells.

\section{I- Quantitative real- time PCR}

According to instructions of manufacture, total RNA was isolated using Qiagen extraction kit (Qiagen, USA). RNA isolation was performed on in vitro cells.

Laryngeal carcinoma cells were centrifuged for $3 \mathrm{~min}$. at full speed. The supernatant was removed and transferred to a new microcentrifuge tube, 1 volume $(350 \mu \mathrm{l})$ of $70 \%$ ethanol was added to the cleared lysate, $700 \mu 1$ of the sample was transferred to an $\mathrm{RN}$ easy spin column placed in a $2 \mathrm{ml}$ collection tube and centrifuged for $15 \mathrm{sec}$. at $\geq 8000 \mathrm{rpm}$.

$700 \mu 1$ Buffer RW1 was transferred to the RN easy spin column and Centrifuged for $15 \mathrm{sec}$. at $\geq 8000 \mathrm{rpm}$ to wash the spin column membrane, $500 \mu 1$ Buffer RPE was added to the RN easy spin column and centrifuged for $15 \mathrm{~s}$ at $\geq 8000 \mathrm{rpm}$ to wash the spin column membrane.

$500 \mu 1$ Buffer RPE was added to the RN easy spin column and centrifuged for $2 \mathrm{~min}$ at $\geq 8000 \mathrm{rpm}$ to wash the spin column membrane, $\mathrm{RN}$ easy spin column was placed in a new $1.5 \mathrm{ml}$ collection tube. 30-50 $\mu 1$ RNase-free water was added directly to the spin column membrane, and centrifuged for $1 \mathrm{~min}$ at $\geq 8000 \mathrm{rpm}$ to elute the RNA.

The eluate was transferred to a new Eppendorf tube and stored at $-80^{\circ} \mathrm{C}$ for further use, The purity (A260/A280 ratio) and the concentration of RNA were obtained using spectrophotometry (dual wavelength Beckman, Spectrophotometer, USA).

Primers sequence for all studied genes in the work

Real-time PCR primers

Forward Reverse

p53 CTACTAAGGTCGTGAGACGCTGCC TCAGCATACAGGTTTCCTTCCACC 106 


\section{Bax CCAGGACGCATCCACCAAGAAGC TGCCACACGGAAGAAGACCTCTCG 136}

Bcl-2 GGATGACTTCTCTCGTCGCTACCGT ATCCCTGAAGAGTTCCTCCACCAC 118

\section{GAPDHATGGAGAAGGCTGGGGCTCACCT AGCCCTTCCACGATGCCAAAGTTGT 209}

\section{cDNA synthesis:}

The total RNA $(0.5-2 \mu \mathrm{g})$ was used for cDNA conversion using high capacity cDNA reverse transcription kit Fermentas, USA).

\section{Reagents and equipment:}

a) Moloney murine leukemia virus (MMLV) reverse transcriptase was used for the synthesis of cDNA from RNA. It is an RNA- dependent DNA polymerase that uses single- stranded RNA as a template in the presence of a primer to synthesize a complementary DNA strand.

b) Human Placental Ribonuclease Inhibitor (HPRI) for inhibition of RNase activity.

c) First strand buffer: Provides preferred $\mathrm{pH}$ and ionic strength for reverse transcription.

d) Deoxynucleotide triphosphate (dNTPs) dATP, dTTP, dGTP, dCTP were used for extension of primers.

e) Random hexamers: primers for reverse transcription of RNA (Stratagene).

f) DEPC- treated water.

g) Thermal cycler (Biometra, USA).

\section{Procedure:}

Three $\mu$ of random primers were added to the $10 \mu \mathrm{l}$ of RNA which was denatured for 5 minutes at $65^{\circ} \mathrm{C}$ in the thermal cycler.

The RNA primer mixture was cooled to $4^{\circ} \mathrm{C}$, The cDNA master mix was prepared according to the kit instructions and was added (for each sample) as follows (table1):

\begin{tabular}{|l|l|}
\hline Component & Volume \\
\hline First strand buffer & $5 \mu \mathrm{l}$ \\
\hline $10 \mathrm{mMdNTPs}$ & $2 \mu \mathrm{l}$ \\
\hline RNase inhibitor $(40 \mathrm{U} / \mu \mathrm{l})$ & $1 \mu \mathrm{l}$ \\
\hline MMLV-RT enzyme $(50 \mathrm{U} / \mu \mathrm{l})$ & $1 \mu \mathrm{l}$ \\
\hline DEPC-treated water & $10 \mu \mathrm{l}$ \\
\hline
\end{tabular}

The total volume of the master mix was $19 \mu \mathrm{l}$ for each sample. This was added to the $31 \mu \mathrm{RNA}$ primer mixture resulting in $50 \mu \mathrm{l}$ of cDNA.

The last mixture was incubated in the programmed thermal cycler for one hour at $37^{\circ} \mathrm{C}$ followed by inactivation of enzymes at $95^{\circ} \mathrm{C}$ for 10 minutes and finally cooled at $4^{\circ} \mathrm{C}$. Then RNA was changed into cDNA. The converted cDNA was stored at $-20{ }^{\circ} \mathrm{C}$.

\section{Real-time qPCR using SYBR Green I:}

Real-time qPCR amplification and analysis were performed using an Applied Biosystem with software version 3.1 (StepOne ${ }^{\mathrm{TM}}$, USA). The qPCR assay with the primer sets was optimized at the annealing temperature. All cDNA were in duplicate and including previously prepared samples

\section{Preparation of the reaction master mix for Q-PCR:}

TABLE (2) For each sample the following reagents and volumes were added:

\begin{tabular}{|l|l|}
\hline PCR reaction mix component & Volume \\
\hline Forward Primer & $1 \mu \mathrm{l}$ \\
\hline Reverse Primer & $1 \mu \mathrm{l}$ \\
\hline Syber green mix & $12.5 \mu \mathrm{l}$ \\
\hline cDNA template & $5 \mu \mathrm{l}$ \\
\hline RNAse free water & $5.5 \mu \mathrm{l}$ \\
\hline Total volume & $25 \mu 1$ \\
\hline
\end{tabular}


TABLE (3) Running condition for RT-PCR:

\begin{tabular}{|l|l|l|l|}
\hline \multirow{2}{*}{ System } & \multicolumn{3}{|l|}{ Thermal cycling condition } \\
\cline { 2 - 4 } & Stage & Temp. & Time \\
\hline \multirow{4}{*}{$\begin{array}{l}\text { Applied Biosystems } \\
\text { StepOne } \\
\text { Real-Time PCR } \\
\text { System }\end{array}$} & Hold & $50^{\circ} \mathrm{C}$ & $2: 00$ \\
\cline { 2 - 4 } & One cycle & $0: 15$ \\
\cline { 2 - 4 } & Denaturation & $95^{\circ} \mathrm{C}$ & $1: 00$ \\
\cline { 2 - 4 } & Annealing & $60^{\circ} \mathrm{C}$ & $1: 00$ \\
\cline { 2 - 4 } & Extension & $72^{\circ} \mathrm{C}$ & \multicolumn{2}{|l}{} \\
\cline { 2 - 4 } & 40 cycles & \multicolumn{2}{|l}{} \\
\cline { 2 - 4 } & &
\end{tabular}

Calculation of Relative Quantification (RQ) (relative expression):

\section{Definitions of the terms found in the analysis}

\section{Endogenous control}

The control is the gene that does not vary between all of the samples tested.

\section{Calibrator}

The calibrator is the sample that all others are compared to. It's the "untreated", or "time zero". The RQ of the calibrator is 1 because it does not vary compared to itself.

$$
\mathrm{Ct}=\mathrm{PCR} \text { cycle }
$$

A typical q PCR run has around 40 cycles. The $\mathrm{Ct}$ is the value where the PCR curve crosses the threshold, in the linear part of the curve. It's the value that will be used for the analysis.

\section{Endogenous controls}

Typically have a smaller $\mathrm{Ct}$ then regular genes.

$\Delta \mathrm{Ct}=\mathrm{Ct}$ gene test $-\mathrm{Ct}$ endogenous control

$\Delta \Delta \mathrm{Ct}=\Delta \mathrm{Ct}$ sample $1-\Delta \mathrm{Ct}$ calibrator

$\mathrm{RQ}=$ Relative quantification $=2^{-\Delta \Delta C t}$

The RQ is a technique used to analyze the fold changes in gene expression in a given sample compared to a calibrator; a reference sample (such as an untreated control sample, time zero, etc.).

\section{Statistical analysis}

The results of five separate experiments were collected. Values were shown as means \pm standard deviations (SD). Data were analyzed by SPSS software version 16 using paired samples $t$ test. $p<0.05$ was considered to be statistically significant.

\section{RESULTS}

The effect of the extract on the growth of cancer cells was evaluated at two different time intervals (24 and 48h). The growth inhibitory effect of the extract on the cells was time-dependent. At increased time intervals, high levels of growth inhibition were observed

We observed no anti-proliferative effects on the healthy cell line.

Anti-proliferative effects of Salvia are represented by an increased expression of BAX, P53 and decreased expression of BCL-2 genes (Table 4, fig 1).

TABLE (4) Statistical expression of BAX, P53, and BCL-2 in Hep-2 cell line after 24hours and 48 hours.

\begin{tabular}{|l|l|l|l|}
\hline Experment $n=5$ & Mean & St diviation & p. value \\
\hline Bax 24 hours & 4.06 & \multirow{2}{*}{0.19} & $0.000^{*}$ \\
\cline { 1 - 2 } Bax 48 hours & 5.34 & & \\
\hline Bc12 24 hours & 0.48 & \multirow{2}{*}{0.04} & $0.001^{*}$ \\
\hline Bcl2 48 hours & 0.35 & & \\
\hline P53 24 hours & 6.40 & \multirow{2}{*}{0.27} & $0.005^{*}$ \\
\hline P53 48 hours & 7.06 & & \\
\hline
\end{tabular}

* = significant 


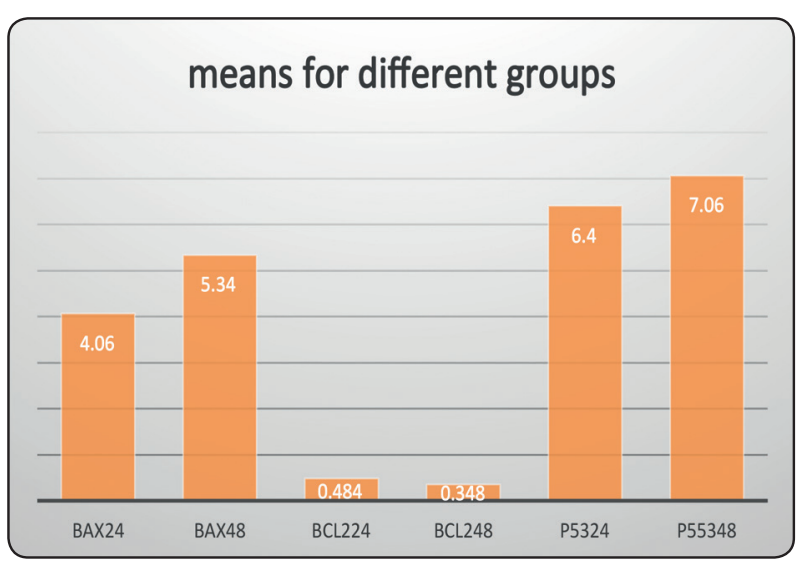

Fig. (1) Bar chart containing the mean value of the different groups

\section{DISCUSSION}

Salvia or Sage has been used for a long time as an herbal medicine that possesses a lot of therapeutic properties, including anticancer effects ${ }^{17}$. It is used for the relief of pain and oral inflammation. It is also useful for mild dyspepsia and minor skin inflammation. It comes in various forms as tea, liquid, and dry extract ${ }^{18}$.

The origin of Salvia name is from Latin- word (salvare) which means to cure or to save ${ }^{19}$.

The composition of essential oil of Salvia varies according to the environmental, seasonal and genetic factors ${ }^{14}$. Essential oils are considered as valuable sources for antimicrobial, antioxidant and anticancer agents ${ }^{15}$. Common sage contains the highest amount of essential oil in comparison to other species of Salvia ${ }^{20,21}$.

Salvia extract can inhibit angiogenesis, invasion, and metastasis of tumor cells in vivo, which may help in the development of anti-angiogenic drugs ${ }^{12}$.

Drinking of salvia herbal tea can inhibit colon cancer in rats and induced DNA damage ${ }^{22}$.

According to Hamidpour et al., 2014 the normal use of sage is very safe. However, there are no studies about the adverse effect of using Salvia in excessive amount despite their usage for many centuries ${ }^{23}$.

Cancer is characterized by uncontrolled proliferation of cells which may spread to other parts of the body ${ }^{12}$. Angiogenesis is an important factor for the proliferating and spreading of malignant cells ${ }^{24}$.

Tumor growth rate depends on the balance between apoptosis, and proliferation at the whole process of carcinogenesis ${ }^{23}$.

Apoptosis is a type of programmed cell death, which counteracts the growth of tumors. A lot of chemotherapy drugs trigger apoptosis to achieve antitumor effects ${ }^{25}$.

Apoptosis process is controlled genetically. The p53 tumor suppressor gene mutation is an important event in the development of malignancy. Cells with a mutated p53 gene tend to escape from apzwqswaoptosis due to inactivation of $\mathrm{p} 53$ protein ${ }^{26}$.

Inhibition of apoptosis promotes the beginning of carcinogenesis and cancer development ${ }^{27}$.

The p53 gene has a lot of mechanisms to reach anticancer effect. It has the ability to trigger growth arrest by restraining the cell cycle at the G1/S checkpoint when DNA damage is recognized. This enables the fixation of DNA damage. If DNA damage is irreparable, p53 can trigger apoptosis ${ }^{28}$.

Apoptosis is also associated with the expression of two synergistically acting genes that encode antiapoptotic and pro- apoptotic proteins. Bcl-2 gene promotes cell survival, and Bax gene enhances apoptosis ${ }^{27,29,30}$.

In a study of Paul-Samojednya et al., 2005, the apoptotic frequency (represented by the expression of Bax gene) was inversely proportional to the decreased expression of $\mathrm{Bcl}-2$ gene ${ }^{31}$. Bax associated proteins are dominant inhibitors of the action of $\mathrm{Bcl}-2^{32}$.

The two genes Bcl-2 and Bax genes are associated with the late signaling phase of apoptosis. 
The carcinogenic potential of $\mathrm{Bcl}-2$ contributes to the accumulation of cells with damaged DNA that should be eradicated in normal conditions ${ }^{32,33}$.

Reactivation or restoration of the function of p53 will have marked therapeutic benefit ${ }^{34}$. Treatment may also lead to decreased levels of mutant p53 by mediating autophagy; the degradation of proteins through lysosomes ${ }^{33-36}$.

There are two major apoptotic pathways, the intrinsic or the mitochondrial pathway and extrinsic or the death receptor pathway ${ }^{37}$.

Initiation the intrinsic apoptosis pathway could be initiated by the decrease of anti-apoptotic proteins, such as Bcl-2 and an increase of the proapoptotic proteins, such as $\mathrm{Bax}^{38}$.

Pro-apoptotic proteins trigger cell death by reducing the mitochondrial membrane potential (Depolarization) ${ }^{39-41}$.

Depolarization of the mitochondrial membrane leads to an increase in its permeability. This process is an important step in the intrinsic apoptotic pathway and is followed by the release of cytochrome $c$ from the mitochondria into the cytosol ${ }^{42}$.

The release of cytochrome $\mathrm{c}$ leads to cleavage of pro-caspase-9. As regarding the extrinsic apoptotic pathway, it is initiated by different death receptors as Fas. Finally, the extrinsic pathway leads to cleavage of pro-caspase- 8 . Cleavage of caspase- 8 causes the release of cytochrome $\mathrm{c}$ from the mitochondria. Cleaved caspase- 8 and caspase- 9 may activate downstream effector caspases, as caspase-3, which destroys the different physiological cellular functions and eventually leads to cell death ${ }^{38}$.

Bax is considered as a key component for initiation of the mitochondrial dysfunction ${ }^{43,44}$.

Cell survival could be stimulated by the antiapoptotic Bcl-2 protein. It inhibits the permeability of the mitochondria and the subsequent release of cytochrome c, so, it can inhibit the apoptosis effectively ${ }^{39,40}$.
The p53 gene plays an important role in activation of apoptosis through triggering the release of cytochrome $c$ from the mitochondria. The study of Martin S 2000, proved that the cytochrome c-releasing activity of p53 needs the presence of cytosolic $\mathrm{Bax}^{45}$

The Bax gene promoter has a binding site for $\mathrm{p} 53$ and seems to be a downstream mediator of p53-dependent apoptosis ${ }^{46}$. The proapoptotic Bax protein accumulates in the mitochondria as a reaction to death signals ${ }^{47}$.

The results of the present study revealed an inhibitory effect of Salvia extract on cancer cell lines by induction of apoptosis represented by increasing the levels of p53 and Bax genes and decrease the levels of Bcl2 gene. These results are in accordance with many previous researches in which Salvia extract exhibited a cytotoxic effect on different malignant cell lines through apoptosis dependent pathway. This included lymphoma and leukemic cells, prostate, liver, bone, oral cavity, esophagus, and cervix malignant cells, human breast cancer cells, human lung cancer cells, human colon cancer cells, human pancreatic cancer cells, melanotic melanoma, and renal adenocarcinoma cells ${ }^{14,41,48,51}$.

In the current work, the growth inhibitory effect of Salvia extract on the cells was time-dependent. At increased time intervals, high levels of growth inhibition were observed as there was an increase in the levels of p53 and BAX and decrease in the levels of Bcl 2 following exposure for $24 \mathrm{~h}$, and $48 \mathrm{~h}$. These results met the results of Zare et al., 2013 and Zhao et al., 2015. They suggested that the induction of apoptosis was time and dose dependent as there was an increase in the percentage of dead malignant cells from 12 to $48 \mathrm{~h}^{41,49}$.

In the present study, Salvia extract induced apoptosis and inhibition of the growth of cancer cell lines with no effect on the growth of normal cell lines. This finding is consistent with previous reports of Zhao et al., 2015 and Itani et al., 2008. They found that the extract induced apoptosis and inhibition of 
the growth of human cancer cell lines with no effect on the growth of normal cell lines. These results are promising since specificity towards cancer cells is important to produce effective anticancer agents ${ }^{11,41}$.

Our study showed increased levels of Bax and decreased levels of $\mathrm{Bcl} 2$ after treatment of malignant cell lines with the extract. These results are in accordance with previous studies of Chiu et al., 2010, Cheng et al., 2010, Tseng et al., 2014, Liu et al., 2015 and Hung et al., 2016. They found that Salvia miltiorrhiza which is found in China induced cell death through the mitochondrial apoptotic pathway. They detected an increase in the ratio of Bax to Bcl-2, a decrease mitochondrial membrane potential, and a release of cytochrome $\mathrm{c}$ in small cell lung cancer cells and human oral cancer cells ${ }^{52-56}$.

Previous studies found that Salvia extract could arrest the growth of nasopharyngeal carcinoma cell lines which are similar to our results ${ }^{57-59}$.

The research of Wei et al.,2012 showed that Salvia caused apoptosis in cancer cells through the activation of the expression of p53 and the subsequent upregulation of Bax. These results are in accordance with the results of the current work in which the levels of p53 and Bax were increased after treatment of cancer cells with Salvia extract ${ }^{60}$.

\section{CONCLUSION}

-Salvia was found to induce growth inhibition of nasopharyngeal cancer cells. The extract was shown to be selective, as it demonstrated no changes in the normal cell line, in comparison with the cancer cell lines.

-Salvia herbal medicines have the potential to become a safe anti-carcinogenic agent. But it should be used carefully until further studies prove the efficiency and safety of it.

For that, meticulous pharmacological and metabolic studies should be applied in future studies.

\section{REFERENCES}

1. Neergheen VS, Bahorun Th, Taylor EW, Jen LS, Aruoma OI. Targeting specific cell signaling transduction pathways by dietary and medicinal phytochemicals in cancer chemoprevention.Toxicology. 2010;278:229-41.

2. Saunders FR, Wallace HM. On the natural chemoprevention of cancer. Plant Physiol Biochem. 2010;48:621-626.

3. Kuppusamy P, Yusoff MM, Maniam GP, Govindan N. A case study regulation and functional mechanisms of cancer cells and control its activity using plants and their derivatives. J Pharm Res. 2013;6:884-892.

4. Portt L, Norman G, Clapp C, Greenwood M, Greenwood MT. Anti-apoptosis and cell survival: a review. Biochim Biophys Acta. 2011;1813:238-259.

5. Sun SY, Hail N, Lotan RJ. Apoptosis as a novel target for cancer chemoprevention. J Natl Cancer Inst. 2004;4:662672 .

6. Thangam R, Sathuvan M, Poongodi A, Suresh V, Pazhanichamy K, Sivasubramanian S, et al. Activation of intrinsic apoptotic signaling pathway in cancer cells by Cymbopogon citratus polysaccharide fractions. Carbohydr Polym. 2014;107:138-150.

7. Felipe KB, Kviecinski MR, da Silva FO, Bücker NF, Farias MS, Porfirio Will Castro LSE, et al. Inhibition of tumor proliferation associated with cell cycle arrest caused by extract and fraction from Casearia sylvestris (Salicaceae) J Ethnopharmacol. 2014;155:1492-1499.

8. Shojaee S, Parhiz H, Eshaghi A, Emami SA, Asili J, Mosaffa F. In vitro protective effects of Scutellaria litwinowii root extract against $\mathrm{H} 2 \mathrm{O} 2$-induced DNA damage and cytotoxicity. J Complement Integr Med. 2014;11:121-127.

9. Ahmadi F, Mojarrab M, Ghazi-Khansari M, Hosseinzadeh L. A semipolar fraction of petroleum ether extract of Artemisia aucheri induces apoptosis and enhances the apoptotic response to doxorubicin in human neuroblastoma SKNMC cell line. Res Pharm Sci.2015;10:335-344.

10. Nikavar B, Abolhasani L, Izadpanah H. Alpha-amylase inhibitory activities of six salvia species. Iran J Pharm Res 2008;7:297-303.

11. Itani WS, El-Banna SH, Hassan SB, Larsson RL, Bazarbachi A, Gali-Mutasib HU. Anti-colon cancer components from Lebanese sage (Salvia Libanotica) essential oil. Cancer Biol Ther 2008;7:1765-73. 
12. Keshavarz M, Bidmeshkipour A, Mostafavi A, Mansouri K, Mohamadi-Motlagh H. Anti tumor activity of Salvia officinalis is due to its anti-angiogenic, anti-migratory and anti-proliferative effects. Cell J 2011;12:477-82.

13. Ayatollahi A, Shojaii A, Kobarfard F, Mohammadzadeh M, Choudhary M. Two flavones from Salvia leriaefolia. Iran J Pharm Res 2009;8:179-84.

14. Hadri A, Gomez Del Rio M, Sanz J, Coloma A, Idaomar M, Ozanas B, et al. Cytotoxic activity of $\alpha$-humulene and transcaryo-phyllene from Salvia officinalis in animal and human tumor cells. An R Acad Nac Farm 2010;76:343-56.

15. Hussain A, Anwar F, Iqbal T, Bhatti I. Antioxidant attributes of four Lamiaceae essential oils. Pak J Bot 2011;43:1315-21.

16. Tayarani-Najaran Z, Asili J, Aioubi E, Emami SA. Growth inhibition and apoptosis induction of Salvia chloroleuca on MCF-7 breast cancer cell line. Iran J Pharm Res.2013;12:789-799.

17. Wu CF, Bohnert S, Thines E, Efferth T. Cytotoxicity of Salvia miltiorrhiza Against Multidrug-Resistant Cancer Cells. Am J Chin Med. 2016;44:871-94.

18. Abu-Lafi S, Sabbobeh R, Hejaz H, Al-Jaas H, et al. Phytochemical Analysis of Cultivated and Wild Salvia Palaestina using GC-MS: A comparative study. World J Pharm Sci 2015; 3: 2348-2356.

19. Keller, M. S. 1978. Mysterious Herbs and Roots, Culver City Calif: Peace Press, CA. 1978: 300-314.

20. Rami K, Li Z. Antimicrobial activity of essential oil of Salvia officinalis L. collected in Syria. Afr J Biotech 2011;10:8397-402.

21. Abu-Lafi S, Hejaz H, Sabbobeh R, Al-Jaas H et al. Essential Oil Secondary Metabolites Variation of Salvia palaestina Leaves Growing wild from Different Locations in Palestine. JAPS 2015;5: 084-089.

22. Pedro DF, Ramos AA, Lima CF, Baltazar F, Pereira-Wilson C. Modulation of DNA damage prevention and signaling pathways in diet induced colon cancer prevention. BMC Proc 2010;4Suppl 2:P58.

23. Hamidpour M, Hamidpour R, Hamidpour S, Shahlari M. Chemistry, Pharmacology, and Medicinal Property of Sage (Salvia) to Prevent and Cure Illnesses such as Obesity, Diabetes, Depression, Dementia, Lupus, Autism, Heart Disease, and Cancer. Journal of Traditional and Complementary Medicine 2014; 4: 82-88.
24. Carmeliet P. Angiogenesis in health and disease. Nat Med 2003;9:653-60.

25. $\mathrm{Hu} \mathrm{W}$, Kavanagh JJ. Anticancer therapy targeting the apoptotic pathway. The Lancet Oncology. 2003;4(12):721729.

26. Rivlin N, Brosh R, Oren M and Varda Rotter V. Mutations in the p53 Tumor Suppressor Gene. Important Milestones at the Various Steps of Tumorigenesis. Genes Cancer. 2011; 2: 466-474.

27. Reed J.C. Mechanisms of apoptosis A.m. J. Pathol.2000; 157 pp. $1415-1426$.

28. Naga Deepthi CH, VVL Pavan Kumar A, Rameshbabu, Indirapriyadarshini U. Role of Tumor Suppressor Protein p53 in Apoptosis and Cancer Therapy. J Cancer Sci Ther.2011; S17:001.

29. S. Cory, J.M. Adams The Bcl 2 family: regulators of the cellular life-or-death switch Nat. Rev., Cancer, 2 (9) (2002), pp. 647-656.

30. T. Kobayashi, H. Sawa, J. Morikawa, W. Zhang, H. Shiku Bax induction activates apoptotic cascade via mitochondria cytochrome c release and Bax of the expression enhances apoptosis induced by chemotherapeutic agents in DLD-1 colon cancer cells Jpn. J. Cancer Res., 91 (12) (2000), pp. 1264-1268.

31. Paul-Samojedny M, Kokocińska D, Samojedny A, Mazurek U, Partyka R et al. Expression of cell survival/death genes: Bcl-2 and Bax at the rate of colon cancer prognosis Biochim Biophys Acta. 2005;1741(1-2):25-9.

32. Cory S, Huang CSD and Adams MJ: The Bcl-2 family: roles in cell survival and oncogenesis. Oncogene. 2003; 22: $8590-8607$.

33. Porebska I, Wyrodek E, Kosacka M, Adamiak J, et al. Apoptotic markers p53, Bcl-2 and Bax in primary lung cancer. In Vivo. 2006 ;20:599-604.

34. Muller PA, Vousden KH. Mutant p53 in Cancer: New Functions and Therapeutic Opportunities. Cancer Cell. 2014; 25: 304-317.

35. Yi Y.W., Kang H.J., Kim H.J., Kong Y., et al. Targeting mutant p53 by a SIRT1 activator YK-3-237 inhibits the proliferation of triple-negative breast cancer cells. Oncotarget.2013;4:984-994.

36. Vakifahmetoglu-Norberg H., Kim M., Xia H.G., Iwanicki M.P., et al. Chaperone-mediated autophagy degrades mutant p53. Genes Dev. 2013;27:1718-1730. 
37. Fulda S., Debatin K.M. Extrinsic versus intrinsic apoptosis pathways in anticancer chemotherapy. Oncogene. 2006; 25:4798-4811.

38. Shalini S., Dorstyn L., Dawar S., Kumar S. Old, new and emerging functions of caspases.Cell Death Differ. 2015;22:526-539.

39. Kroemer G, Reed JC. Mitochondrial control of cell death. Nat Med. 2000;6:513-519.

40. Kutuk O, Letai A. Regulation of Bcl-2 family proteins by posttranslational modifications.Curr Mol Med. 2008; 8:102-118.

41. Zhao Q, Huo XC, Sun FD, Dong RQ. Polyphenol-rich extract of Salvia chinensis exhibits anticancer activity in different cancer cell lines, and induces cell cycle arrest at the G0/G1-phase, apoptosis and loss of mitochondrial membrane potential in pancreatic cancer cells. Mol Med Rep. 2015;12(4):4843-50.

42. Webster KA. Mitochondrial membrane permeabilization and cell death during myocardial infarction: Roles of calcium and reactive oxygen species. Future Cardiol. 2012;8:863-884.

43. Yang L-J, Jeng C-J, Kung H-N, et al. Tanshinone IIA isolated from Salvia miltiorrhizaelicits the cell death of human endothelial cells. Journal of Biomedical Science. 2005;12(2):347-361.

44. Renault T.T., Manon S. Bax: Addressed to kill. Biochimie. 2011;93:1379-1391.

45. Schuler M, Bossy-Wetzel E, Goldstein JC, Fitzgerald et al. p53 Induces Apoptosis By Caspase Activation Through Mitochondrial Cytochrome C Release. The Journal Of Biological Chemistry- Jbc . 2000; 275:7337-7342.

46. Benchimol S. p53-dependent pathways of apoptosis. Cell Death Differ 2001;8:1049-1051.

47. Oda E, Ohki R, Murasawa H, Nemoto J, Shibue $\mathrm{T}$ et al. Noxa, a BH3-only member of the Bcl-2 family and candidate mediator of p53-induced apoptosis. Science 2000;288(5468):1053-8.

48. Loizzo MR, Tundis R, Menichini F, Saab AM, et al. Cytotoxic activity of essential oils from Labiatae and Lauraceae families against in vitro human tumor models. Anticancer Res 2007;27:3293-9.

49. Zare Shahneh F, Valiyari S, Baradaran B, Abdolalizadeh J, Bandehagh A, Azadmehr A, Hajiaghaee R. Inhibitory and Cytotoxic Activities of Salvia Officinalis L. Extract on Human Lymphoma and Leukemia Cells by Induction of Apoptosis. Adv Pharm Bull. 2013; 3(1): 51-55.
50. Chang TW, Lin CY, Tzeng YJ, Lur HS. Synergistic combinations of tanshinone IIA and trans-resveratrol toward cisplatin-comparable cytotoxicity in HepG2 human hepatocellular carcinoma cells. Anticancer Res 2014; 34 : 5473-5480.

51. Lin CY, Chang TW, Hsieh WH, Hung MC, Lin IH, Lai SC, Tzeng YJ. Simultaneous induction of apoptosis and necroptosis by Tanshinone IIA in human hepatocellular carcinoma HepG2 cells. The Cell Death Discov. 2016 ;2:16065.

52. Chiu T.-L., Su C.-C. Tanshinone IIA induces apoptosis in human lung cancer A549 cells through the induction of reactive oxygen species and decreasing the mitochondrial membrane potential. International Journal of Molecular Medicine. 2010;25(2):231-236.

53. Cheng C.-Y., Su C.-C. Tanshinone IIA may inhibit the growth of small cell lung cancer H146 cells by up-regulating the $\mathrm{Bax} / \mathrm{Bcl}-2$ ratio and decreasing mitochondrial membrane potential. Molecular Medicine Reports. 2010;3(4):645-650.

54. Tseng P.-Y., Lu W.-C., Hsieh M.-J., Chien S.-Y., Chen M.$\mathrm{K}$. Tanshinone IIA induces apoptosis in human oral cancer KB cells through a mitochondria-dependent pathway. BioMed Research International. 2014;2014:7.

55. Liu JJ, Wu HH, Chen TH, Leung W, Liang YC. 15,16 Dihydrotanshinone I from the Functional Food Salvia miltiorrhiza Exhibits AnticancerActivity in Human HL-60 Leukemia Cells: in Vitro and in Vivo Studies. Int J Mol Sci. 2015;16(8):19387-400.

56. Hung YC, Pan TL, Hu WL. Roles of Reactive Oxygen Species in Anticancer Therapy with Salvia miltiorrhiza Bunge. Oxid Med Cell Longev. 2016; Aug 4.

57. Yuan S, Wang Y, Chen X, Song Y, Yang Y. A study on apoptosis of nasopharyngeal carcinoma cell line induced by Tanshinone II A and its molecular mechanism. Hua Xi Yi Ke Da Xue Xue Bao. 2002;33(1):84-90.

58. Yuan S-L, Wei Y-Q, Wang X-J, Xiao F, Li S-F, Zhang J. Growth inhibition and apoptosis induction of tanshinone II-A on human hepatocellular carcinoma cells. World Journal of Gastroenterology. 2004;10(14):2024-2028.

59. Zhou L, Chan WK, Xu N, et al. Tanshinone IIA, an isolated compound from Salvia miltiorrhiza Bunge, induces apoptosis in HeLa cells through mitotic arrest. Life Sciences. 2008;83(11-12):394-403.

60. Wei X., Zhou L., Hu L., Huang Y. Tanshinone IIA arrests cell cycle and induces apoptosis in 786-O human renal cell carcinoma cells. Oncology Letters. 2012;3(5):1144-1148. 